\title{
LiNKS BETWEEN MYTHOLOGY AND PHILOSOPHY: HOMER'S ILIAD AND CURRENT CRITERIA OF RATIONALITY
}

\author{
MigueL LÓPEZ-ASTORGA \\ Institute of Humanistic Studies "Juan Ignacio Molina", University of Talca, CHILE \\ milopez@utalca.cl
}

\begin{abstract}
It is usually said that there is a clear difference between pre-philosophical texts such as Homer's Iliad and what is provided in the fragments corresponding to first philosophers such as Thales of Miletus. This paper tries to show that this is not undoubtedly so, and it does that by means of the analysis of a fragment of the Iliad in which Hypnos is speaking. In this way, the main argument is that, while the fragment can be interpreted both in a literal and in a metaphorical or poetic sense, in both of those cases it can be thought that it is related to philosophy or rational thinking. If the interpretation is literal, the fragment expresses an idea very akin to an important thesis by Thales of Miletus. On the other hand, if the interpretation is metaphorical or poetic, we have to assume, following several contemporary reasoning theories, that the fragment is essentially based on an evident rational inference.
\end{abstract}

Keywords: Homer • inference $\bullet$ philosophy $\bullet$ pre-philosophical cosmogony $\bullet$ reasoning

\section{Introduction}

It is often said that a clear separation between myth and $\lambda$ óros (reasoning, argumentation, speech) can be observed (e.g, Burnet 1920, 1964). In this way, it is also habitually stated that philosophy (or, at least, western philosophy) started in Miletus, and, in particular, with Thales, the first philosopher in the western thought history. However, this paper will try to show that this is not necessarily so, and that, even beyond works such as that of Cornford (2004), Most (1999) or Schadewaldt (1981), which seem to propose a continuity, and not a categorical break, between myth and $\lambda$ óros, it is possible to trace absolutely rational processes in pre-philosophical cosmogonies such as those of Homer (of course, if the specialized literature is reviewed, it can be thought that cosmogonies such as those of Hesiod also deserve a similar analysis; however, this paper is mainly focus on Homer and the Iliad.

To do that, I will consider a fragment from the Iliad (14, 244). That fragment presents a scenario in which Hypnos (god of sleep) is speaking, the most important point of what is said by him for this paper being that Oceanus (god of the River Ocean) is the origin of everything. Thus, the analysis will consider two possibilities: 
(a) that statement about Oceanus should be interpreted literally, and (b) that very statement ought to be understood as a metaphor or poetically (a discussion with regard to these two options can be found, e.g., in Kirk \& Raven 1977), which in turn means that the paper will have two basic separate sections.

The first one will address the fragment, and try to make its actual sense explicit and to account for what it exactly implies. By doing so, it will be explained that, if what is written in that fragment is deemed as what Homer wanted to express literally, obvious relationships between it and philosophy, and, especially, Thales of Miletus, can be identified.

On the other hand, the second one will explore the possibility that the fragment can be understood metaphorically. In this case, it will be shown that, if to do that is correct, it has to be accepted, at the same time, the existence of underlying processes of the fragment that can be considered to be rational, or, at a minimum, linked to reasoning and the ability to make inferences. This last point will be explained with the help of several current theories about human cognition. In this way, it will be

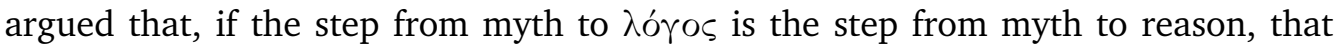
expression is not the most suitable, since there can be also reasoning in the mythic thought.

Thus, this paper is intended to reveal that the boundaries between myth and philosophy are blurred, whether the option chosen is (a) or (b). Accordingly, the next section begins with the fragment and option (a).

\section{Oceanus and water as $\alpha \dot{p} \chi \dot{\eta}$}

As said, the fragment is authored by Homer (thelliad 14, 244), and, in fact, is Fragment 10 in Kirk and Raven (1977). It is originally in Greek as follows:

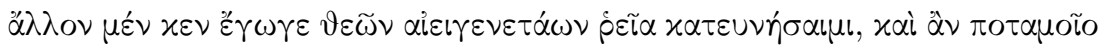

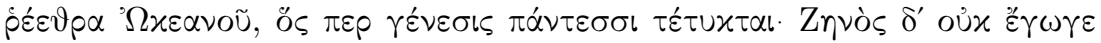

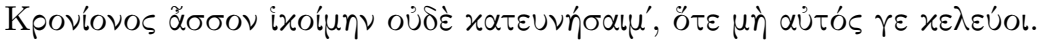

As also stated, who is talking is Hypnos and a translation of it can be this one:

Another of the everlasting gods would I easily send to sleep, even the streams of river Okeanos who is the begetter of all: but Zeus son of Kronos would I not approach, nor send to sleep, except that he himself so bid me (translation by Kirk \& Raven 1977, p.15).

Clearly, the part of this fragment that is interesting for the aims of this paper is "o" $\varsigma$

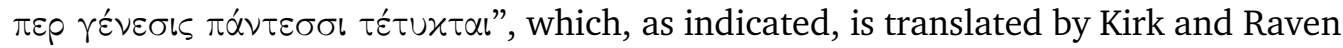
(1977, p.15) as "who is the begetter of all" and can also be translated as, for example, 'who is the origin of everything'. And this part is relevant because, as claimed too, 
two interpretations, which are reviewed by Kirk and Raven as well, are possible. One of them is (a), and what is important about this last option is its evident relationship to Thales of Miletus.

Indeed, speaking about 'origin' seems to be speaking about $\alpha \rho \chi \hat{\eta}$, that is, about the first element that all the things come from, and, as it is well known, Thales of Miletus thought that that first element was water. This is especially obvious if some ancient passages Kirk and Raven comment on too are taken into account. Two of them can be, for example, those of Aristotle in De Caelo B 13, 294 a 28 and in Metaphysica A 3, 983 b 6 (in fact, as it is also known, the concept of apx $\dot{\eta}$ should be assigned narrowly mainly to the Aristotelian Metaphysica A), which are in turn Fragment 86 and 87 respectively in Kirk and Raven (1977). Nevertheless, what appears to be truly relevant about this is that, given the direct relationship between Oceanus and water, several writers, including ancient philosophers such as Aristotle and maybe even Plato, understood that there were clear links between the statement about Oceanus in Fragment 10 in Kirk and Raven (1977) and Thales' thesis on water. And this seems to be so because a literal reading of this last fragment can lead to the idea that, as provided by Thales of Miletus later, everything around the world comes from water.

In fact, Kirk and Raven (1977) also appear to refer to texts such as the one of Plato in Teeteto 152 E (Fragment 11 in Kirk \& Raven 1977) and the one of Aristotle in Metaphysica A 3, 983 b 27 (Fragment 12 in Kirk \& Raven 1977) to support the idea that these last thinkers actually linked what is said by Hypnos in the Iliad to what was claimed by Thales of Miletus about water. Certainly, such texts are very illustrative. The first one is the following:

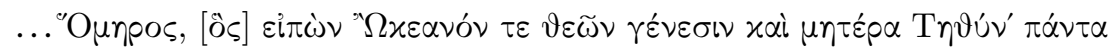

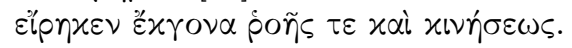

And its English translation can be, for example, this one:

... Homer, who by saying 'Okeanos begetter of gods and mother Tethys' declared all things to be offspring of flux and motion (translation by Kirk \& Raven 1977, p.16).

On the other hand, the second text claims:

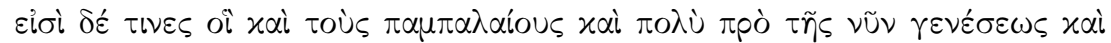

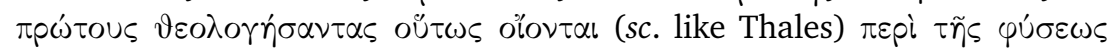

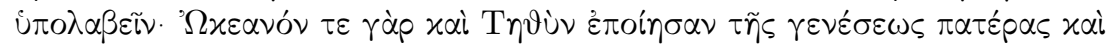

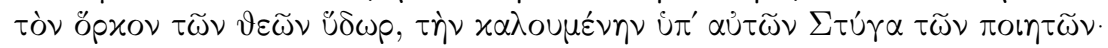

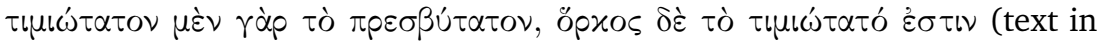
brackets in the version of Fragment 12 in Kirk \& Raven 1977, p.16-7).

And a translation can be as follows: 
There are some who think that the very ancient and indeed first speculators about the gods, long before the present age, made the same supposition about nature (sc. as Thales); for they wrote that Okeanos and Tethys were the parents of coming-to-be, and the oath of the gods water - that which by the poets themselves is called Styx; for what is oldest is most honourable, and the most honourable thing is used as an oath (translation by Kirk and Raven 1977, p.16-7; brackets in text).

Nevertheless, the point is that, if all of this is so, the general approach given in texts such as that of Cornford (2004), that of Most (1999), or that of Schadewaldt (1981) becomes correct. Certainly, beyond the fact that other ancient Greek philosophers such as Parmenides of Elea or Xenophanes of Colophon resorted to elements clearly mythical (see, e.g., Most 1999), there would be no categorical rupture between myth and $\lambda$ ó ${ }^{\prime}$ s if the aforementioned links existed. In this way, what would have to be held is that the step from the former to the latter did not happen in a particular and clear moment, and that, although it is often considered to have occurred with Thales of Miletus, the fragment of the Iliad analyzed above shows that that is only a conventional agreement.

However, (b) can be another option. The problem is that, in this second case, the distinction between myth and $\lambda$ ó $\gamma \circ \varsigma$ is even less clear. The next section explains this based on some contemporary theories on reasoning.

\section{Fragment 10 in Kirk and Raven (1977) and reasoning}

Verily, if the alternative adopted is (b), the situation is very akin. In that case, it cannot be said that the difference between the fragment by Homer commented on in the previous section and the arguments provided by Thales of Miletus is exactly the difference that can be seen between myth and $\lambda$ óros either. And this is so at least if $\lambda$ óros is understood as rational thought. Evidently, rational thought refers to reason and reason in turn refers to reasoning, and, following what has been proposed by several frameworks about reasoning in recent times, it has to be acknowledged that, if interpreted in a poetic way, there is an underlying reasoning of Fragment 10 in Kirk and Raven (1977). Let us examine what can be said about this last fragment from the perspective of three of such frameworks.

One of them could be the one that considers reasoning to be generally made in accordance with classical logic and applying a number of formal rules such as those that are to be found in works such as those of Gentzen $(1934,1935)$ or Deaño (1999). From this point of view, it is absolutely clear that a metaphoric interpretation of "Os

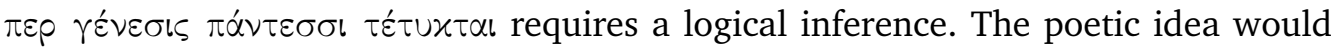
be that, from the fact that Oceanus is the god of water and there is no life without 
water, it can be said that, if Oceanus does not exist, there cannot be life. Of course, the fragment does not speak only about living beings, but about everything that exists. Nevertheless, as far as I understand them, following Kirk and Raven (1977), it can be stated that the poetic sense of the fragment would refer just to the living beings, and not to everything around the universe. Thus, the underlying inference would be obvious if the following equivalences were assumed:

$\rightarrow$ : conditional

$\neg$ : negation

$p$ : 'there is water'

$q$ : 'there is life'

$r$ : 'Oceanus exists'

In this way, it could be thought that the poetic interpretation is supported by, for example, two premises with logical forms such as these ones:

$$
\text { [I]: } \neg p \rightarrow \neg q
$$

[II]: $\neg r \rightarrow \neg p$

This would imply that, under the assumption that Oceanus did not exist $(\neg r), \neg p$ could be drawn via Modus Ponendo Ponens (i.e., the rule $[x \rightarrow y, x] \therefore$ y, where ' $\because$ ' means that $y$ can be derived from $[x \rightarrow y, x]$ ) from $\neg r$ and [II]. Nonetheless, this would in turn allow inferring $\neg q$, via Modus Ponendo Ponens too, from $\neg p$ and [I], the final result being that, if Oceanus did not exist $(\neg r)$, then there would b no life $(\neg q)$.

Clearly, this last conclusion, whose logical form is $\neg r \rightarrow \neg q$, could be understood as a formula indicating that the living beings live because Oceanus, which, as pointed out, would reveal a logical inference under (b), and, therefore, reasoning under (b), and, hence, גóros under (b). The only difficulty in this regard would be that, nowadays, it is very hard to propose that the human mind basically pays attention to classical logic when making inferences. And the reason for this is that several experiments have proven that this logic has certain characteristics and requirements that are inconsistent with people's real behavior (see, e.g., Johnson-Laird; Khemlani \& Goodwin 2015).

However, there are also approaches that have taken this difficulty into account and have presented a more developed framework. That is the case of the mental logic theory (e.g., Braine \& O'Brien 1998a; Gouveia et al. 2003; O'Brien 2009, 2014; O'Brien \& Li 2013), which has already been used to analyze ancient philosophies too (e.g., López-Astorga 2015). This theory claims that human beings have a mental logic, but, in its proponents' view, that logic is not absolutely identical to classical logic. There are important differences between them. For example, the mental logic 
theory states that empirical evidence suggests that human beings do not consider the conditional in the same manner as classical logic, that is, in the material way (see, e.g., Braine \& O'Brien 1998b). However, perhaps what is more important here is that none of the differences between the logic of the mental logic theory and classical logic has an influence on the arguments and the inference above based on the latter.

The mental logic theory admits all the elements that are necessary for those arguments and that inference. For example, the theory refers to pragmatic premises coming from general knowledge (e.g., Braine \& O'Brien 1998c), which is absolutely compatible with the acceptance of formulae such as [I] and [II] as premises, and deems Modus Ponendo Ponens as one of the basic reasoning schemata habitually used by people (see, e.g., Braine \& O'Brien 1998d). So, if the mental logic theory is assumed, it can also be said that there is a logical and rational thought related to the poetic interpretation of the fragment by Homer above, and that, accordingly, the distinction between myth and $\lambda$ óros is not clear. Once premises such as [I] and [II] have been accepted, the conclusion $\neg r \rightarrow \neg q$ can be drawn in a natural and easy way.

But it can be thought that the mental logic theory may not be the most accepted reasoning framework at present either. However, although this were truly so, nor would it be an actual problem. The result is not very different if the theory adopted is an approach with much more empirical support and supporters. Obviously, a theory of this kind can be the mental models theory (e.g., Hinterecker; Knauff \& JohnsonLaird 2016; Johnson-Laird; Khemlani \& Goodwin 2015; Quelhas \& Johnson-Laird 2017; Quelhas; Rasga \& Johnson-Laird 2017; Ragni; Sonntag, Johnson-Laird 2016), which has already been taken as an instrument to review ancient philosophical proposals as well (e.g., López-Astorga 2017). That this theory is today more accepted that frameworks such as that of the mental logic theory can be checked in the specialized literature. There are a number of problems that, in general, theories such as the one of mental logic cannot clearly solve and that, nevertheless, do not cause difficulties to the mental models theory. One of them can be, for example, that people do not always apply rules such as Modus Ponendo Ponens or Modus Tollendo Tollens (i.e., the rule $[x \rightarrow y, \neg y] \therefore \neg x$ ) to expressions in natural language with the structure 'if...then'. As said, it is hard to account for, from the mental logic theory, exactly when (and why this is so) people use these rules. However, the mental models theory can do that with no difficulties (see, e.g., Johnson-Laird \& Byrne 2002; López-Astorga 2016). Another example can be that of the logical rule allowing introducing a disjunction (i.e., the rule $x \therefore[x \vee y]$, or $y \therefore[x \vee y]$, where ' $\vee$ ' stands for, evidently, disjunction). The situation is akin to the previous one. Individuals only apply this rule in certain occasions, and it seems that only the mental models theory can clearly show which those occasions are (e.g., Orenes \& Johnson-Laird 2012).

Nonetheless, maybe what is most important for this paper is that this is a psycho- 
logical theory with philosophical roots, in particular, based on some Peirce's (19311958) ideas, one of them being that of iconicity (e.g., Johnson-Laird; Khemlani \& Goodwin 2015, p.207). In this way, according to this framework, people never use logical forms when reasoning. They only iconically represent models of the reality. Such iconic models consist of different possible scenarios and individuals tend to accept those that are consistent and to reject those that are incoherent. Thus, given the relationships between Oceanus, water, and life corresponding to interpretation (b) commented on above, these eight combinations of possibilities could be thought for those three elements:

[1]: (Oceanus) \& (Water) \& (Life)

[2]: (Oceanus) \& (Water) \& (Not-Life)

[3]: (Oceanus) \& (Not-Water) \& (Life)

[4]: (Oceanus) \& (Not-Water) \& (Not-Life)

[5]: (Not-Oceanus) \& (Water) \& (Life)

[6]: (Not-Oceanus) \& (Water) \& (Not-Life)

[7]: (Not-Oceanus) \& (Not-Water) \& (Life)

[8]: (Not-Oceanus) \& (Not-Water) \& (Not-Life)

Obviously, [1] to [8] are eight different alternative scenarios and the differences between them are clear. In [1], Oceanus exists, there is water, and there is life. However, in [2], while Oceanus also exists and there is water too, there is no life. In [3], what is missing is only water. On the other hand, in [4] only Oceanus exists. [5] is a universe without Oceanus but with water and life. [6] represents a situation in which there is only water. Likewise, in [7] there is only life. Finally, in [8] there is nothing (neither Oceanus nor water nor life).

Nevertheless, it is very probable that, if an individual thinks about the fragment of the Iliad that is being analyzed, he/she does not consider all of these eight possibilities. Regardless of the fact that, according to the mental models theory, people often represent just what is true, and not what is false (e.g., Johnson-Laird; Khemlani \& Goodwin 2015; there is no doubt that this is a strong thesis from the philosophical point of view and that can be traced in the history of western thought; however, the mental models theory is, as stated, a psychological theory and appears to assume this idea based upon the experimental results of the studies carried out by its proponents), in the fragment it is assumed that Oceanus (and, of course, other gods) exists, which means that, in practice, possibilities [5] to [8] would be ignored (in them, Oceanus does not exist). On the other hand, [3] and [4] would be also rejected because they are incoherent. They are so because, if Oceanus exists, there is water, and, in them, although Oceanus does exist, there is no water. Lastly, empirical experience would eliminate [2] as well, since this last scenario stands for a situation in which there is 
no life, and we empirically know that there does be life. So, only [1] is acceptable, that is, an iconic alternative in which, as said, not only Oceanus exists, but there are both water and life too. And, if the mental models theory is assumed as a correct framework, that is the result, again, of reasoning, that is, of a rational process, that is, of $\lambda$ óros. Furthermore, as in the cases of the two previous approaches, the fact that only it is possible to think about life in a scenario in which Oceanus is also real can lead one to understand that the latter is the cause of the former, which can in turn be related to (b) and show, in the same way, that, certainly, under this last poetic interpretation, the limits between myth and philosophy are not evident either.

\section{Conclusions}

Accordingly, the boundaries between mythic thought and rationality are not obvious, and it seems that the pre-philosophical texts do not enable to identify such boundaries in a clear way. At least, that is what the passage by Homer taken from the Iliad that has been dealt with in this paper appears to show. And this is so whether the fragment is interpreted literally or metaphorically.

True, as explained, in the case of (a), there would not be doubt that there would be relationships to important theses by Thales of Miletus. Ancient thinkers such as Aristotle, and perhaps, as pointed out, Plato, already saw this, which causes proposals such as the one of Cornford (2004), Most (1999), or Schadewaldt (1981) to make sense.

Nevertheless, if interpretation (b) is the suitable one, as also accounted for, the

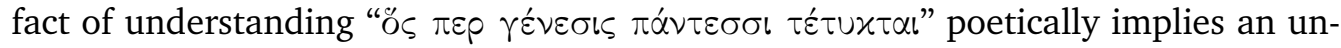
derlying action of rationality and rational thought. This is so following at least three contemporary cognitive frameworks, which reveal that, given some particular assumptions (in the case reviewed here, for example, the existence of Oceanus), the conclusions people tend to derive from them are often rational. Therefore, following such frameworks (one of them, the mental models theory, is, as said, very accepted today and has many proponents), the characteristics that differentiate philosophy from myth cannot be the ability to infer or rational consistency, as those characteristics can also be found in mythic thought.

Hence it seems that it is necessary to look for differences in other directions, but, as this paper appears to reveal too, that task may not be easy. Following theses similar to those of Cornford (2004), Most (1999), or Schadewaldt (1981), one might claim that all the elements often assigned to mythic thought can always be related, in a more or less evident way, to fragments corresponding to presocratic philosophers. Likewise, one might also think that it may not be hard to identify, even if it is in a latent way, all the characteristics usually attributed to philosophy in pre-philosophical 
cosmogonies. Furthermore, as it is well known, much has been written about these issues, and, as works such as, for example, some of those cited above demonstrate, this paper is not the first study of them at all. However, notwithstanding this fact, it seems that there are not clear answers yet. So, a possibility that undoubtedly deserves to be deemed is that the difference between philosophy (at least, the presocratic philosophy) and myth is not as real as thought.

\section{References}

Braine, M. D. S. \& O'Brien, D. P. (ed.) 1998a. Mental Logic. Mahwah: Lawrence Erlbaum Associates, Inc., Publishers.

Braine, M. D. S. \& O'Brien, D. P. 1998b. A theory of if: A lexical entry, reasoning program, and pragmatic principles. In: M. D. S. Braine \& D. P. O’Brien (ed.), Mental Logic, p.199-244. Mahwah: Lawrence Erlbaum Associates, Inc., Publishers.

- 1998c. How to investigate mental logic and the syntax of thought. In: M. D. S. Braine \& D. P. O’Brien (ed.), Mental Logic, p.45-61. Mahwah: Lawrence Erlbaum Associates, Inc., Publishers.

- 1998d. The theory of mental-propositional logic: Description and illustration. In: M. D. S. Braine \& D. P. O’Brien (ed.), Mental Logic, p.79-89. Mahwah: Lawrence Erlbaum Associates, Inc., Publishers.

Burnet, J. 1920. Early Greek Philosophy. London: A. \& C. Black, Ltd. 1964. Greek Philosophy: Thales to Plato. London: MacMillan \& Company Ltd.

Cornford, F. M. 2004. From Religion to Philosophy: A Study in the Origins of Western Speculation. Mineola: Dover Publications, Inc.

Deaño, A. 1999. Introducción a la lógica formal. Madrid: Alianza Editorial.

Gentzen, G. 1934. Untersuchungen über das logische Schließen I. Mathematische Zeitschrift 39(2): 176-210.

- 1935. Untersuchungen über das logische Schließen II. Mathematische Zeitschrift 39(3): 405-31.

Gouveia, E. L.; Roazzi, A.; O’Brien, D. P; Moutinho, K. \& Bompastor Borges Dias, M. G. 2003. Raciocínio dedutivo e lógica mental. Estudos de Psicologia 20(3): 135-45.

Hinterecker, T.; Knauff, M. \& Johnson-Laird, P. N. 2016. Modality, probability, and mental models. Journal of Experimental Psychology: Learning, Memory, and Cognition 42(10): 1606-20.

Johnson-Laird, P. N. \& Byrne, R. M. J. 2002. Conditionals: A theory of meaning, pragmatics, and inference. Psychological Review 109(4): 646-78.

Johnson-Laird, P. N.; Khemlani, S. \& Goodwin, G. P. 2015. Logic, probability, and human reasoning. Trends in Cognitive Sciences 19(4): 201-14.

Kirk, G. S. \& Raven, J. E. 1977. The Presocratic Philosophers: A Critical History with a Selection of Texts. London \& New York: Cambridge University Press.

López-Astorga, M. 2015. Chrysippus' indemonstrables and mental logic. Croatian Journal of Philosophy 15(43): 1-15. 
2016. Logic, pragmatics, and types of conditionals. Frontiers of Philosophy in China 11(2): 279-97.

2017. Thales of Miletus and the semantic possibilities of his view of the soul. Aisthema IV(1): 101-12.

Most, G. 1999. The poetics of early Greek philosophy. In: A. Long (ed.), The Cambridge Companion to Early Greek Philosophy (Cambridge Companions to Philosophy), p.332-62. Cambridge: Cambridge University Press.

O'Brien, D. P. 2009. Human reasoning includes a mental logic. Behavioral and Brain Sciences 32: 96-7.

- 2014. Conditionals and disjunctions in mental-logic theory: A response to Liu and Chou (2012) and to López-Astorga (2013). Universum 29(2): 221-35.

O'Brien, D. P. \& Li, S. 2013. Mental logic theory: A paradigmatic case of empirical research on the language of thought and inferential role semantics. Journal of Foreign Languages 36(6): 27-41.

Orenes, I. \& Johnson-Laird, P. N. 2012. Logic, models, and paradoxical inferences. Mind \& Language 27(4): 357-77.

Peirce, C. S. 1931-1958. Collected papers of Charles Sanders Peirce. C. Hartshorne; P. Weiss \& A. Burks (ed.). Cambridge: Harvard University Press.

Quelhas, A. C. \& Johnson-Laird, P. N. 2017. The modulation of disjunctive assertions. The Quarterly Journal of Experimental Psychology 70(4): 703-17.

Quelhas, A. C.; Rasga, C. \& Johnson-Laird, P. N. 2017. A priori true and false conditionals. Cognitive Science 41(55): 1003-30.

Ragni, M.; Sonntag, T. \& Johnson-Laird, P. N. 2016. Spatial conditionals and illusory inferences. Journal of Cognitive Psychology 28(3): 348-65.

Schadewaldt, W. 1981. Die Anfänge der Philosophie bei den Griechen. Die Vorsokratiker und ihre Voraussetzungen. Tijdschrift Voor Filosofie 43(2): 377-8.

\section{Acknowledgments}

This paper is a result of the project CONICYT/FONDECYT/REGULAR/FOLIO № 1180013 , "Recuperación de las formas lógicas de los enunciados a partir de un análisis de las posibilidades semánticas a las que hacen referencia", supported by the National Fund for Scientific and Technological Development (FONDECYT, following its initials in Spanish), Government of Chile. 